\title{
2 Prediction of contralateral breast cancer: external validation of risk 3 calculators in 20 international cohorts
}

4 Daniele Giardiello ${ }^{1,2} \cdot$ Michael Hauptmann $^{3,4} \cdot$ Ewout W. Steyerberg $^{2,5} \cdot$ Muriel A. Adank $^{6} \cdot$ Delal Akdeniz $^{7}$. 5 Jannet C. Blom ${ }^{7}$. Carl Blomqvist ${ }^{8,9} \cdot$ Stig E. Bojesen ${ }^{10,11,12} \cdot$ Manjeet K. Bolla $^{13} \cdot$ Mariël Brinkhuis $^{14}$. 6 Jenny Chang-Claude ${ }^{15,16} \cdot$ Kamila Czene $^{17}$. Peter Devilee ${ }^{18,19}$. Alison M. Dunning ${ }^{20}$. Douglas F. Easton ${ }^{13,20}$. 7 Diana M. Eccles ${ }^{21}$ • Peter A. Fasching 22,23 · Jonine Figueroa 24,25,26 • Henrik Flyger ${ }^{27}$ • Montserrat García-Closas ${ }^{26,28}$. 8 Lothar Haeberle ${ }^{23}$. Christopher A. Haiman ${ }^{29} \cdot$ Per Hall ${ }^{17,30}$. Ute Hamann ${ }^{31}$. John L. Hopper ${ }^{32}$.

9 Agnes Jager ${ }^{33}$. Anna Jakubowska ${ }^{34,35}$. Audrey Jung ${ }^{15}$ - Renske Keeman ${ }^{1}$ • Linetta B. Koppert ${ }^{36}$. Iris Kramer ${ }^{1}$. 10 Diether Lambrechts ${ }^{37,38}$. Loic Le Marchand ${ }^{39}$. Annika Lindblom ${ }^{40,41}$. Jan Lubiński ${ }^{34}$. Mehdi Manoochehri ${ }^{31}$. 11 Luigi Mariani $^{42} \cdot$ Heli Nevanlinna ${ }^{43} \cdot$ Hester S. A. Oldenburg ${ }^{44} \cdot$ Saskia Pelders $^{7}$. Paul D. P. Pharoah ${ }^{13,20}$. 12 Mitul Shah ${ }^{20}$. Sabine Siesling ${ }^{45}$. Vincent T. H. B. M. Smit ${ }^{18} \cdot$ Melissa C. Southey $^{46,47}$. William J. Tapper ${ }^{48}$. 13 Rob A. E. M. Tollenaar ${ }^{49}$. Alexandra J. van den Broek ${ }^{1}$. Carolien H. M. van Deurzen ${ }^{50}$. Flora E. van Leeuwen ${ }^{51}$. 14 Chantal van Ongeval ${ }^{52} \cdot$ Laura J. Van't Veer $^{1} \cdot$ Qin Wang ${ }^{13} \cdot$ Camilla Wendt $^{53} \cdot$ Pieter J. Westenend $^{54}$.

15 Maartje J. Hooning ${ }^{7} \cdot$ Marjanka K. Schmidt ${ }^{1,51,55}$

Received: 17 December 2019 / Accepted: 21 March 2020

(c) Springer Science+Business Media, LLC, part of Springer Nature 2020

\begin{abstract}
Background Three tools are currently available to predict the risk of contralateral breast cancer (CBC). We aimed to compare the performance of the Manchester formula, CBCrisk, and PredictCBC in patients with invasive breast cancer (BC). Methods We analyzed data of 132,756 patients ( $4682 \mathrm{CBC}$ ) from 20 international studies with a median follow-up of 8.8 years. Prediction performance included discrimination, quantified as a time-dependent Area-Under-the-Curve (AUC) at 5 and 10 years after diagnosis of primary $\mathrm{BC}$, and calibration, quantified as the expected-observed $(\mathrm{E} / \mathrm{O})$ ratio at 5 and 10 years and the calibration slope.

Results The AUC at 10 years was: 0.58 (95\% confidence intervals [CI] 0.57-0.59) for CBCrisk; 0.60 (95\% CI 0.59-0.61) for the Manchester formula; 0.63 (95\% CI 0.59-0.66) and 0.59 (95\% CI 0.56-0.62) for PredictCBC-1A (for settings where $B R C A 1 / 2$ mutation status is available) and PredictCBC-1B (for the general population), respectively. The E/O at 10 years: 0.82 (95\% CI 0.51-1.32) for CBCrisk; 1.53 (95\% CI 0.63-3.73) for the Manchester formula; 1.28 (95\% CI 0.63-2.58) for PredictCBC-1A and 1.35 (95\% CI 0.65-2.77) for PredictCBC-1B. The calibration slope was 1.26 (95\% CI 1.01-1.50) for CBCrisk; 0.90 (95\% CI 0.79-1.02) for PredictCBC-1A; 0.81 (95\% CI 0.63-0.99) for PredictCBC-1B, and 0.39 (95\% CI 0.34-0.43) for the Manchester formula.
\end{abstract}

Conclusions Current CBC risk prediction tools provide only moderate discrimination and the Manchester formula was poorly calibrated. Better predictors and re-calibration are needed to improve CBC prediction and to identify low- and high-CBC risk patients for clinical decision-making.

Keywords Contralateral breast cancer $\cdot$ Risk prediction $\cdot$ Validation $\cdot$ Clinical decision-making

\section{Introduction}

Electronic supplementary material The online version of this article (https://doi.org/10.1007/s10549-020-05611-8) contains supplementary material, which is available to authorized users.

Marjanka K. Schmidt

mk.schmidt@nki.nl

Extended author information available on the last page of the article
A rising number of women with breast cancer (BC) are at risk to develop a new primary tumor in the contralateral breast (CBC) with consequently another cancer treatment and potentially less favorable prognosis [1]. Although $\mathrm{CBC}$ incidence is low ( $0.4 \%$ per year) in the general $\mathrm{BC}$

\begin{tabular}{|l|l|l|l|l|}
\hline Journal : Large 10549 & Article No : 5611 & Pages : 12 & MS Code : 5611 & Dispatch : 30-3-2020 \\
\hline
\end{tabular}


population, contralateral preventive mastectomy $(\mathrm{CPM})$ is increasing, also among women with low-CBC risk [2-5].

Three tools are tools currently available to predict the risk of $\mathrm{CBC}$, although probably none are widely used: (1) the Manchester formula; (2) CBCrisk, and (3) PredictCBC [6-8]. The Manchester group in the United Kingdom (UK) proposed a set of guidelines for counseling women about CPM [8]. Based on a systematic review of the literature, they devised a formula to estimate lifetime $\mathrm{CBC}$ risk based on age at first primary $\mathrm{BC}$, family history of $\mathrm{BC}$, estrogen-receptor (ER) status, diagnosis of ductal carcinoma in situ (DCIS), and oophorectomy.

The second tool, CBCrisk, was developed using data on $1921 \mathrm{CBC}$ cases and 5763 matched controls with primary BC [7]. The model uses data on age at first BC diagnosis, age at first birth, first degree family history of BC, high-risk pre-neoplasia, breast density (obtained using the BI-RADS system), ER status, first BC type (pure invasive, pure DCIS, a mix of the two, unknown), and adjuvant endocrine therapy. External validation was performed using two independent studies in the United States (US) of 5185 and 6035 patients with 111 and $117 \mathrm{CBC}$ events [7, 9]. A web-based application provides individualized prediction of CBC risk [10].

Third, PredictCBC was developed, cross-validated and evaluated using data from 132,756 patients with first BC and 4672 CBC events, as part of an international collaboration [5]. PredictCBC predicts CBC risk as a function of family history (first degree) of primary $\mathrm{BC}$, and information of primary BC diagnosis: age, nodal status, size, grade, morphology, ER status, human epidermal growth factor receptor 2 (HER2) status, administration of adjuvant or neoadjuvant chemotherapy, adjuvant endocrine therapy, adjuvant trastuzumab therapy, and radiotherapy. Two versions were developed: PredictCBC version 1A includes presence or absence of a mutation in the $B R C A 1$ or $B R C A 2$ genes, an important determinant of $\mathrm{CBC}[5,11,12]$, while PredictCBC version $1 \mathrm{~B}$ was developed for untested patients.

External validation in different studies is relevant to assess the prediction performance of prediction models [13]. Our aim was to perform a head-to-head comparison between CBCrisk, PredictCBC and the Manchester formula. We hereto used several large population- and hospital-based studies used to develop and cross-validate the PredictCBC models.

\section{Material and methods}

External validation of CBCrisk and the Manchester formula was performed in 20 studies: four with individual patient data from the Netherlands [the Amsterdam Breast Cancer Study (ABCS), the Breast Cancer Outcome Study of Mutation carriers (BOSOM), the Erasmus MC Breast Cancer
Registry (EMC), the Netherlands Cancer Registry (NCR)]; and 16 other studies of the Breast Cancer Association Consortium (BCAC). The latter is an international consortium of 102 studies comprising 182,898 patients (data version: January 2017) with a primary BC diagnosed between 1939 and 2016 [14]. Of these, 16 non-familial BC BCAC studies including invasive non-metastatic European-descent female patients with first primary invasive BC diagnosed from 1990 onwards, and with at least $10 \mathrm{CBC}$ events, were included in the analyses [14]. Details about studies and patient selection, and data imputation were described previously [5].

The outcome was in situ or invasive metachronous CBC. Follow-up started 3 months after invasive first primary $\mathrm{BC}$ diagnosis, to exclude synchronous $\mathrm{CBCs}$, and ended at date of CBC, distant metastasis (but not at loco-regional relapse), CPM or last date of follow-up (due to death, being lost to follow-up, or end of study), whichever occurred first. In the BCAC, 27,155 patients were recruited more than 3 months after diagnosis of the first primary BC (prevalent cases); for these patients, follow-up started at date of recruitment (left truncation). Distant metastasis and death due to any cause were competing events.

The Manchester formula provides an estimate of a woman's individual lifetime CBC risk. To assess the prediction $\mathbf{A Q 2} \quad 5$ performance, we translated the lifetime $\mathrm{CBC}$ risk to 5- and 116 10-year CBC risks (see Supplementary Material). The pre- 117 dictors included in the CBC risk estimation in the Manches- 118 ter formula, CBCrisk and PredictCBC models are provided 119 in Table 1. Predictors that were sporadically missing were 120 multiply imputed as described elsewhere [5].

\section{Statistical analysis}

Discrimination, the ability of the model to differentiate between patients who experienced CBC and those who did not, was calculated by time-dependent Area-Underthe-Curve (AUCs) based on Inverse Censoring Probability Weighting at 5 and 10 years $[15,16]$. Values of AUCs close to 1 indicate good discrimination while values close to 0.5 indicate poor discrimination (a coin flip). Calibration is the agreement between observed and predicted risk and is commonly characterized by calibration-in-the-large and slope statistic. Calibration-in-the-large characterizes the overall difference between the observed and predicted risks. It was calculated using the expected/observed (E/O) ratio. An E/O less than 1 indicates that the model systematically underestimates $\mathrm{CBC}$ risk, while an $\mathrm{E} / \mathrm{O}$ above 1 indicates that the model systematically overestimates CBC risk. The expected number of cases was calculated by summing the individual predicted probabilities at 5 and 10 years, based on the patient-specific covariate values [17]. The observed number of cases was estimated by the non-parametric CBC cumulative incidence at 5 and 10 years. The calibration slope was 
Table 1 Predictors included in current contralateral breast cancer risk prediction tools

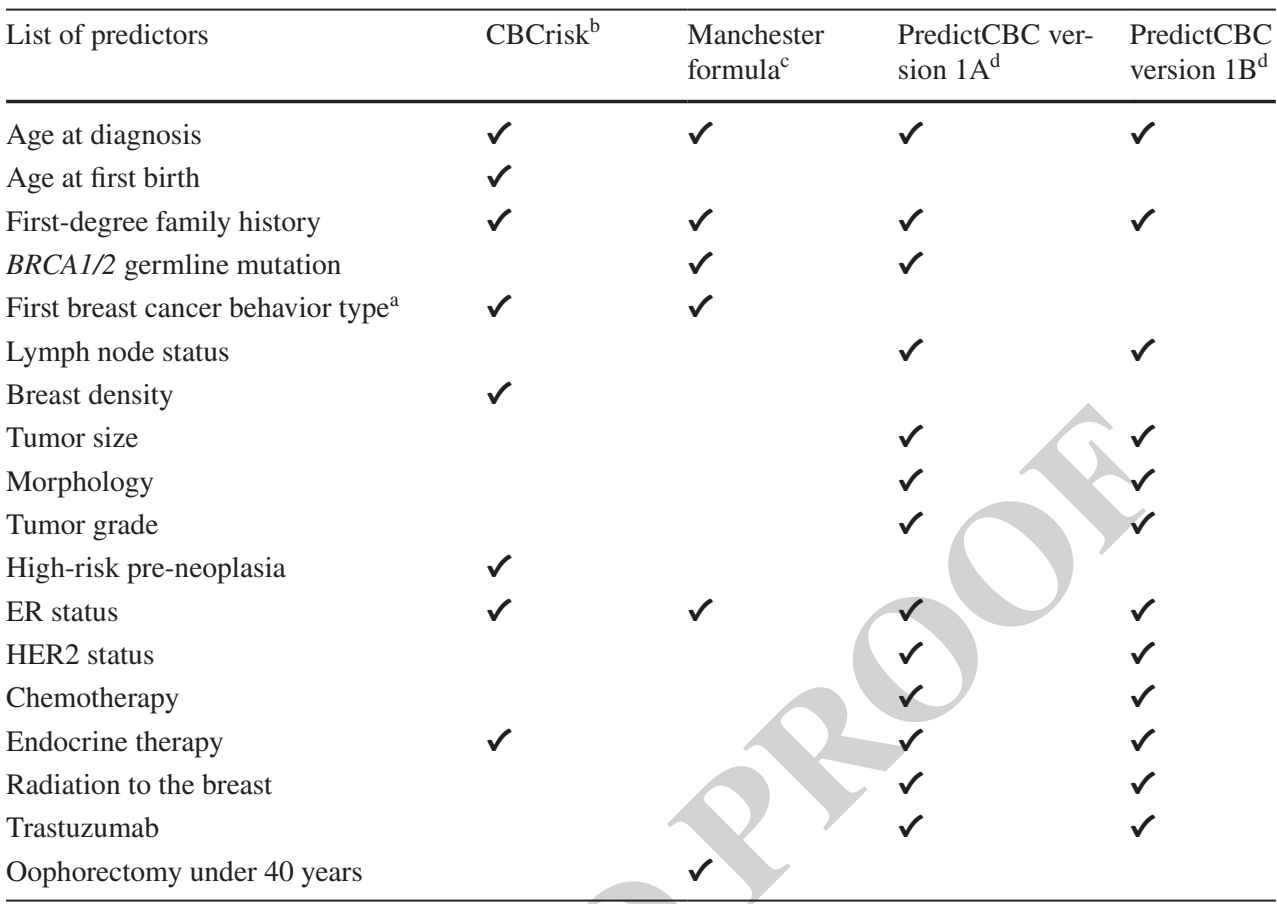

ER estrogen-receptor status, HER2 human epidermal growth factor receptor 2

${ }^{a}$ Contralateral breast cancer risk was calculated including women diagnosed with ductal carcinoma in situ

${ }^{\mathrm{b}}$ Chowdhury et al. [7]

${ }^{\mathrm{c}}$ Basu et al. [8]

${ }^{\mathrm{d}}$ Giardiello et al. [5]

estimated using a Fine and Gray regression model using the linear predictor of the prediction tools. The linear predictor was vs constructed as the sum of the factors included in each model weighted by the corresponding regression coefficients (or parameters), and then computed in the validation dataset exactly as reported for the development set. The calibration slope is determined as the regression coefficient for this linear predictor when fitted as a single covariate in a regression model of disease outcome in the validation dataset. A well-calibrated model should have a calibration slope of 1 ; slopes $<1$ indicate that coefficients were too optimistic for the validation setting [18]. Calibration results were graphically displayed.

Analyses were stratified by geographic groups of studies, since stratification by individual studies would provide too few events in some strata $[5,13,19]$. To allow for heterogeneity across multiple studies, random-effect meta-analyses were performed. We calculated $95 \%$ confidence intervals (CI) and $95 \%$ prediction intervals (PI), which indicate the likely range for prediction accuracy of the model in a new dataset, for discrimination and calibration measures. A sensitivity analysis was performed to check the consistency of CBCrisk performance measures when metachronous CBC was defined as an event after 6 instead of 3 months since the first BC diagnosis. More details are provided in the
Supplementary Material. All analyses were implemented using SAS (SAS Institute Inc., NC, USA) and R software [20].

\section{Results}

We included 132,756 patients from 20 studies who experienced $4862 \mathrm{CBC}$ events during a median follow-up of 8.8 years. The main patient and clinical characteristics across studies and geographic areas are shown in Table 2. $0.57-0.61 ; 95 \%$ PI $0.54-0.64)$ and 0.58 (95\% CI 0.57-0.59; 95\% PI 0.55-0.61) for CBCrisk (Fig. 1); 0.61 (95\% CI $0.60-0.62$; 95\% PI 0.59-0.63) and 0.60 (95\% CI 0.59-0.61; 95\% PI 0.58-0.62) for the Manchester formula (Fig. 2). The E/O ratio at 5 and 10 years was close to 1 for all models: 0.86 (95\% CI $0.50-1.46$; $95 \%$ PI $0.20-3.75)$ and 0.82 (95\% CI $0.51-1.32$; 95\% PI 0.21-3.14) for CBCrisk (Table 3); 1.54 (95\% CI $0.61-3.92$; $95 \%$ PI 0.11-20.72, Table 4), and 1.53 (95\% CI $0.63-3.73$; 95\% PI $0.13-18.52)$ for the Manchester formula (Table 4); 1.26 (95\% CI 0.57-2.77; 95\% PI 0.14-11.34), and 1.28 (95\% CI $0.63-2.58 ; 95 \%$ PI 0.18-9.18) for PredictCBC-1A (Table 5); 1.33 (95\% CI $0.59-2.99,95 \%$ PI $0.14-12.76$ ), 1.35 (95\% CI 0.65-2.77;
172
The AUCs at 5 and 10 years was around 0.6: 0.59 (95\% CI

\begin{tabular}{|l|l|l|l|l|}
\hline Journal : Large 10549 & Article No : 5611 & Pages : 12 & MS Code : 5611 & Dispatch : 30-3-2020 \\
\hline
\end{tabular}


Table 2 Description of main patient and clinical factors used for evaluation of the models and formula

\begin{tabular}{|c|c|c|c|c|c|c|c|}
\hline $\begin{array}{l}\text { Study/geographic } \\
\text { area }\end{array}$ & Europe - other ${ }^{\mathrm{b}}$ & $\begin{array}{l}\text { Europe-Scan- } \\
\text { dinavia }\end{array}$ & $\begin{array}{l}\text { Europe-United } \\
\text { Kingdom }\end{array}$ & $\begin{array}{l}\text { Netherlands- } \\
\text { BOSOM }\end{array}$ & $\begin{array}{l}\text { Netherlands- } \\
\text { EMC }\end{array}$ & $\begin{array}{l}\text { Netherlands- } \\
\text { NCR }\end{array}$ & $\begin{array}{l}\text { United States } \\
\text { and Australia }\end{array}$ \\
\hline$N$ & 15,183 & 12,928 & 11,921 & 3760 & 3390 & 83,138 & 2436 \\
\hline \multicolumn{8}{|l|}{$\begin{array}{l}\text { Age at first diagno- } \\
\text { sis, years }(\%)\end{array}$} \\
\hline$<30$ & $152(1.0)$ & $46(0.4)$ & $156(1.3)$ & $108(2.9)$ & $46(1.4)$ & $388(0.5)$ & $41(1.7)$ \\
\hline $30-39$ & $1252(8.2)$ & $489(3.8)$ & $1811(15.2)$ & $842(22.4)$ & $374(11.0)$ & $4241(5.1)$ & $494(20.3)$ \\
\hline $40+$ & $13,779(90.8)$ & 12,393 (95.9) & 9954 (83.5) & $2810(74.7)$ & 2970 (87.6) & $78,509(94.4)$ & 1901 (78.0) \\
\hline $\begin{array}{l}\text { Age at first } \\
\text { birth = unknown } \\
(\%)\end{array}$ & $15,183(100.0)$ & $12,928(100.0)$ & $11,921(100.0)$ & $3760(100.0)$ & $3390(100.0)$ & $83,138(100.0)$ & $2436(100.0)$ \\
\hline \multicolumn{8}{|l|}{ Family history (\%) } \\
\hline Yes & $2123(14.0)$ & $818(6.3)$ & $1371(11.5)$ & 737 (19.6) & $591(17.4)$ & $0(0.0)$ & $319(13.1)$ \\
\hline No & $8057(53.1)$ & $3158(24.4)$ & $8210(68.9)$ & $1177(31.3)$ & $2482(73.2)$ & $0(0.0)$ & $1498(61.5)$ \\
\hline Unknown & $5003(33.0)$ & $8952(69.2)$ & $2340(19.6)$ & $1846(49.1)$ & $317(9.4)$ & $83,138(100.0)$ & $619(25.4)$ \\
\hline $\begin{array}{l}\text { First BC type }=\text { Pure } \\
\text { invasive }(\%)\end{array}$ & $15,183(100.0)$ & $12,928(100.0)$ & $11,921(100.0)$ & $3760(100.0)$ & $3390(100.0)$ & $83,138(100.0)$ & $2436(100.0)$ \\
\hline $\begin{array}{l}\text { Breast den- } \\
\text { sity = unknown } \\
(\%)\end{array}$ & $15,183(100.0)$ & $12,928(100.0)$ & $11,921(100.0)$ & $3760(100.0)$ & $0(100.0)$ & $83,138(100.0)$ & $2436(100.0)$ \\
\hline \multicolumn{8}{|l|}{ ER status (\%) } \\
\hline Negative & $3387(22.3)$ & 1746 (13.5) & $1718(14.4)$ & $896(23.8)$ & $842(24.8)$ & $14,591(17.6)$ & 445 (18.3) \\
\hline Positive & $10,071(66.3)$ & $9401(72.7)$ & $7175(60.2)$ & $2024(53.8)$ & 2427 (71.6) & $64,790(77.9)$ & $1572(64.5)$ \\
\hline Unknown & 1725 (11.4) & $1781(13.8)$ & $3028(25.4)$ & $840(22.3)$ & $121(3.6)$ & $3757(4.5)$ & 419 (17.2) \\
\hline $\begin{array}{l}\text { High-risk pre-neo- } \\
\text { plasia = unknow } \\
n(\%)\end{array}$ & $15,183(100.0)$ & $12,928(100.0)$ & $11,921(100.0)$ & $3760(100.0)$ & $3390(100.0)$ & $83,138(100.0)$ & $2436(100.0)$ \\
\hline \multicolumn{8}{|l|}{$\begin{array}{c}\text { Anti-estrogen } \\
\text { therapy }(\%)\end{array}$} \\
\hline Yes & $7868(51.8)$ & $6434(49.8)$ & $8712(73.1)$ & 809 (21.5) & $1559(46.0)$ & $40,214(48.4)$ & 363 (14.9) \\
\hline No & $4570(30.1)$ & $1947(15.1)$ & $2046(17.2)$ & $2739(72.8)$ & $1821(53.7)$ & $42,924(51.6)$ & $8(0.3)$ \\
\hline Unknown & $2745(18.1)$ & $4547(35.2)$ & $1163(9.8)$ & $212(5.6)$ & $10(0.3)$ & $0(0.0)$ & $2065(84.8)$ \\
\hline \multicolumn{8}{|l|}{$\begin{array}{l}\text { CBC cumulative } \\
\text { incidence }(\%)\end{array}$} \\
\hline 3-year (95\% CI) & $1.0(0.8-1.2)$ & $0.7(0.5-0.9)$ & $0.5(0.3-0.7)$ & $1.7(1.3-2.1)$ & $1.7(1.2-2.1)$ & $1.3(1.2-1.4)$ & $1.8(0.8-2.8)$ \\
\hline 5-year $(95 \%$ CI) & $1.6(1.4-1.9)$ & $1.0(0.8-1.3)$ & $1.0(0.8-1.3)$ & $3.0(2.5-3.6)$ & $2.6(2.1-3.2)$ & $2.4(2.3-2.5)$ & $2.8(1.7-3.8)$ \\
\hline 10 -year $(95 \%$ CI $)$ & $3.5(3.1-3.9)$ & $2.1(1.7-2.4)$ & $1.3(1.0-1.5)$ & $5.5(4.7-6.2)$ & $5.7(4.9-6.6)$ & $4.6(4.5-4.8)$ & $4.1(3.0-5.3)$ \\
\hline
\end{tabular}

More details about the main patient and clinical characteristics by study are available in the supplementary information of [5]

BOSOM Breast Cancer Outcome Study of Mutation carriers, EMC Erasmus Medical Center, NCR Netherlands Cancer Registry, BC breast cancer, $E R$ estrogen receptor, $C B C$ contralateral breast cancer, $C I$ confidence interval

${ }^{a}$ The studies denoted with Europe and United States and Australia are part of the Breast Cancer Association Consortium

${ }^{\mathrm{b}}$ Europe - other geographic area included studies from Belgium (1), Germany (2), Netherlands (2) and Poland (2)

95\% PI 0.19-10.24) for PredictCBC-1B (Table 5) [5]. The calibration slope was close to 1 for CBCrisk $(1.26,95 \%$ CI 1.01-1.50 and 95\% PI 1.01-1.50, Tables 3, 4, 5), and PredictCBC-1A and 1B 0.90 (95\% CI 0.79-1.02; 95\% PI $0.73-1.08$ ), and 0.81 (95\% CI $0.63-0.99 ; 95 \%$ PI $0.50-1.12$ ) (Table 5), while prognostic effects were far too large for the Manchester formula (slope: $0.39,95 \%$ CI $0.34-0.43,95 \%$ PI 0.34-0.43, Tables 4, 5). Calibration plots of CBCrisk at 5 and 10 years are shown in Supplementary Fig. 1 and
Supplementary Fig. 2. As reported previously [5], the AUCs at 5 and 10 years for PredictCBC-1A were 0.63 (95\% CI $0.58-0.67$, 95\% PI 0.52-0.74), and 0.63 (95\% CI 0.59-0.66, 95\% PI 0.53-0.72), respectively; for PredictCBC-1B 0.59 (CI $0.54-0.63$, 95\% PI 0.46-0.71, Table 5), and 0.59 (95\% CI $0.56-0.62$, 95\% PI 0.52-0.66, Table 5), respectively.

Sensitivity analysis showed that the performance measures of CBCrisk did not change when metachronous CBC was defined after 6 months since first $\mathrm{BC}$ diagnosis (see

\begin{tabular}{|l|l|l|l|l|}
\hline Journal : Large 10549 & Article No : 5611 & Pages : 12 & MS Code : 5611 & Dispatch : 30-3-2020 \\
\hline
\end{tabular}




\author{
Area Under the Curve at 5 years \\ Europe - Other \\ Europe - Scandinavia \\ Europe - UK \\ Netherlands - BOSOM \\ Netherlands - EMC \\ Netherlands - NCR \\ US and Australia \\ Meta-analysis \\ Area Under the Curve at 10 years \\ Europe - Other \\ Europe - Scandinavia \\ Europe - UK \\ Netherlands - BOSOM \\ Netherlands - EMC \\ Netherlands - NCR \\ US and Australia \\ Meta-analysis
}

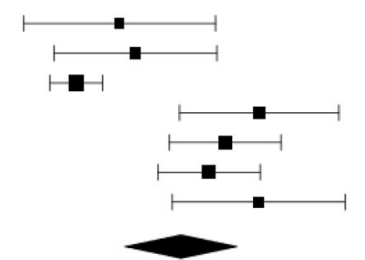

$0.57[0.54,0.60]$

$0.57[0.55,0.60]$

$0.55[0.54,0.56]$

$0.62[0.59,0.65]$

$0.61[0.59,0.63]$

$0.60[0.58,0.62]$

$0.62[0.59,0.65]$

$0.59[0.57,0.61]$

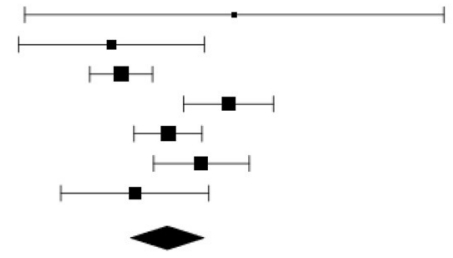

$0.60[0.53,0.68]$

$0.56[0.53,0.59]$

$0.56[0.55,0.57]$

$0.60[0.58,0.62]$

$0.58[0.57,0.59]$

$0.59[0.57,0.61]$

$0.57[0.54,0.59]$

$0.58[0.57,0.59]$

$\begin{array}{cccc}0.5 & 0.55 \quad 0.6 \quad 0.65 & 0.7\end{array}$

Fig. 1 Prediction performance of the CBCrisk model (Chowdhury et al. [7]). The upper and lower panel show the discrimination assessed by a time-dependent Area-Under-the-Curve at 5 and 10 years, respectively. The black squares indicate the estimated accuracy of a model built on all remaining studies or geographic areas.
The black horizontal lines indicate the corresponding 95\% confidence intervals of the estimated accuracy (interval whiskers). The black diamonds indicate the mean with the corresponding $95 \%$ confidence interval of the predictive accuracy

Validation dataset

AUC $[95 \% \mathrm{Cl}]$

\author{
Area Under the Curve at 5 years \\ Europe - Other \\ Europe - Scandinavia \\ Europe - UK \\ Netherlands - BOSOM \\ Netherlands - EMC \\ Netherlands - NCR \\ US and Australia \\ Meta-analysis
}

Area Under the Curve at 10 years

Europe - Other

Europe - Scandinavia

Europe - UK

Netherlands - BOSOM

Netherlands - EMC

Netherlands - NCR

US and Australia

Meta-analysis

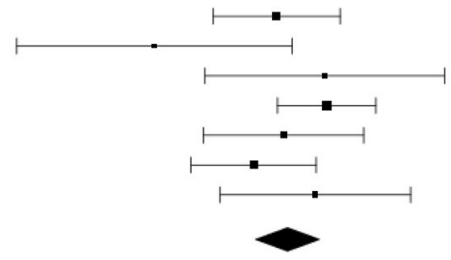

$0.60[0.58,0.63]$

$0.56[0.50,0.61]$

$0.62[0.58,0.67]$

$0.62[0.60,0.64]$

$0.61[0.58,0.64]$

$0.60[0.57,0.62]$

$0.62[0.58,0.66]$

$0.61[0.60,0.62]$

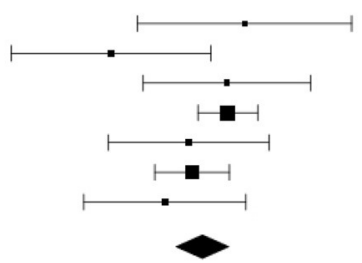

$0.62[0.58,0.66]$

$0.57[0.53,0.60]$

$0.61[0.58,0.64]$

$0.61[0.60,0.62]$

$0.60[0.56,0.63]$

$0.60[0.58,0.61]$

$0.59[0.56,0.62]$

$0.60[0.59,0.61]$

$\begin{array}{ccccc}0.5 & 0.55 & 0.6 & 0.65 & 0.7 \\ & \text { Area Under the Curve }\end{array}$

Fig. 2 Prediction performance of the Manchester formula (Basu et al. [8]) The upper and lower panel show the discrimination assessed by a time-dependent Area-Under-the-Curve at 5 and 10 years, respectively. The black squares for each dataset indicate the estimated accuracy of a model built on all remaining studies or geographic areas. The black horizontal lines indicate the corresponding 95\% confidence intervals of the estimated accuracy (interval whiskers). The black diamonds indicate the mean with the corresponding $95 \%$ confidence interval of the predictive accuracy

\begin{tabular}{|l|l|l|l|l|}
\hline Journal : Large 10549 & Article No : 5611 & Pages : 12 & MS Code : 5611 & Dispatch : 30-3-2020 \\
\hline
\end{tabular}


Table 3 Calibration performance of the $\mathrm{CBC}$ risk model
Table 4 Calibration performance of the Manchester formula

\begin{tabular}{llll}
\hline Validation dataset & E/O ratio at 5 years $(95 \%$ CI $)$ & $\begin{array}{l}\text { E/O ratio at } \\
10 \text { years }(95 \% \text { CI })\end{array}$ & Calibration slope $(95 \%$ CI $)$ \\
\hline Europe-Other & $0.87(076$ to 0.98$)$ & $0.75(0.68$ to 0.81$)$ & $1.11(0.40$ to 1.83$)$ \\
Europe-Scandinavia & $1.59(1.28$ to 1.91$)$ & $1.23(1.08$ to 1.38$)$ & $0.86(0.16$ to 1.57$)$ \\
Europe-UK & $1.35(1.38$ to 2.17$)$ & $1.82(1.53$ to 2.11$)$ & $0.85(-0.03$ to 1.73$)$ \\
Netherlands-BOSOM & $0.45(0.37$ to 0.53$)$ & $0.50(0.43$ to 0.57$)$ & $1.34(0.76$ to 1.93$)$ \\
Netherlands-EMC & $0.48(0.38$ to 0.57$)$ & $0.43(0.37$ to 0.50$)$ & $1.19(0.65$ to 1.73$)$ \\
Netherlands-NCR & $0.57(0.54$ to 0.59$)$ & $0.54(0.52$ to 0.56$)$ & $1.40(1.11$ to 1.68$)$ \\
US and Australia & $0.43(0.33$ to 0.54$)$ & $0.56(0.45$ to 0.67$)$ & $1.13(0.25$ to 2.00$)$ \\
Meta-analysis & $0.86(0.50$ to 1.46$)$ & $0.82(0.51$ to 1.32$)$ & $1.26(1.01$ to 1.50$)$ \\
95\% PI & 0.20 to 3.75 & 0.21 to 3.14 & 1.01 to 1.50 \\
\hline
\end{tabular}

Chowdhury et al. [7]

E/O expected-observed, $C I$ confidence interval, UK United Kingdom, BOSOM Breast Cancer Outcome Study of Mutation carriers, EMC Erasmus Medical Center, NCR Netherlands Cancer Registry, PI prediction interval

\begin{tabular}{llll}
\hline Validation dataset & E/O ratio at 5 years $(95 \%$ CI $)$ & $\begin{array}{l}\text { E/O ratio at } \\
10 \text { years }(95 \% \mathrm{CI})\end{array}$ & Calibration slope $(95 \% \mathrm{CI})$ \\
\hline Europe-Other & $1.64(1.44$ to 1.85$)$ & $1.46(1.34$ to 1.58$)$ & $0.40(0.29$ to 0.50$)$ \\
Europe-Scandinavia & $2.61(2.09$ to 3.12$)$ & $2.11(1.85$ to 2.37$)$ & $0.35(0.13$ to 0.57$)$ \\
Europe-UK & $3.34(2.60$ to 4.08$)$ & $3.49(2.93$ to 4.05$)$ & $0.42(0.23$ to 0.61$)$ \\
Netherlands-BOSOM & $0.81(0.66$ to 0.96$)$ & $0.92(0.79$ to 1.05$)$ & $0.45(0.33$ to 0.56$)$ \\
Netherlands-EMC & $0.94(0.75$ to 1.14$)$ & $0.87(0.75$ to 1.00$)$ & $0.35(0.21$ to 0.49$)$ \\
Netherlands-NCR & $1.00(0.95$ to 1.04$)$ & $1.01(0.98$ to 1.05$)$ & $0.37(0.33$ to 0.42$)$ \\
US and Australia & $0.77(0.58$ to 0.96$)$ & $1.02(0.82$ to 1.23$)$ & $0.51(0.33$ to 0.68$)$ \\
Meta-analysis & $1.54(0.61$ to 3.92$)$ & $1.53(0.63$ to 3.73$)$ & $0.39(0.34$ to 0.43$)$ \\
95\% PI & 0.11 to 20.72 & 0.13 to 18.52 & 0.34 to 0.43 \\
\hline
\end{tabular}

Basu et al. [8]

E/O expected-observed, $C I$ confidence interval, $U K$ United Kingdom, BOSOM Breast Cancer Outcome Study of Mutation carriers, EMC Erasmus Medical Center, NCR Netherlands Cancer Registry, PI prediction interval

Table 5 Summary of prediction performance of CBCrisk, Manchester formula, and PredictCBC version 1A and version 1B with the corresponding $95 \%$ prediction intervals $(\mathrm{PI})$

\begin{tabular}{|c|c|c|c|c|}
\hline Characteristics & CBCriska & Manchester formula $^{\mathrm{b}}$ & PredictCBC version $1 \mathrm{~A}^{\mathrm{c}, \mathrm{d}}$ & PredictCBC version $1 \mathrm{~B}^{\mathrm{c}, \mathrm{d}}$ \\
\hline \multicolumn{5}{|l|}{ Discrimination } \\
\hline AUC at 5 years $(95 \% \mathrm{PI})$ & $0.59(0.54$ to 0.64$)$ & $0.61(0.59$ to 0.63$)$ & $0.63(0.52$ to 0.74$)$ & $0.59(0.46$ to 0.71$)$ \\
\hline AUC at 10 years $(95 \% \mathrm{PI})$ & $0.58(0.55$ to 0.61$)$ & $0.60(0.58$ to 0.62$)$ & $0.63(0.53$ to 0.72$)$ & $0.59(0.52$ to 0.66$)$ \\
\hline \multicolumn{5}{|l|}{ Calibration } \\
\hline $\mathrm{E} / \mathrm{O}$ ratio at 5 years $(95 \% \mathrm{PI})$ & $0.86(0.20$ to 3.75$)$ & $1.54(0.11$ to 20.72$)$ & $1.26(0.14$ to 11.34$)$ & $1.33(0.14$ to 12.76$)$ \\
\hline $\mathrm{E} / \mathrm{O}$ ratio at 10 years $(95 \% \mathrm{PI})$ & $0.82(0.21$ to 3.14$)$ & 1.53 (0.13 to 18.52$)$ & $1.28(0.18$ to 9.18$)$ & $1.35(0.19$ to 10.24$)$ \\
\hline Slope (95\% PI) & $1.26(1.01$ to 1.50$)$ & $0.39(0.34$ to 0.43$)$ & 0.90 (0.73 to 1.08$)$ & 0.81 (0.50 to 1.12$)$ \\
\hline
\end{tabular}

$A U C$ Area under the curve, PI prediction interval

${ }^{a}$ Chowdhury et al. [7]

${ }^{b}$ Basu et al. [8]

${ }^{\mathrm{c}}$ Giardiello et al. [5], Fig. 1 and Figure S5

d version $1 \mathrm{~A}$ includes $B R C A$ mutation status as a variable while $1 \mathrm{~B}$ does not

\begin{tabular}{|l|l|l|l|l|}
\hline Journal : Large 10549 & Article No : 5611 & Pages : 12 & MS Code : 5611 & Dispatch : 30-3-2020 \\
\hline
\end{tabular}


Supplementary Materials, Supplementary Tables 1-2 and Supplementary Fig. 3).

\section{Discussion}

Accurate $\mathrm{CBC}$ risk predictions are essential in clinical decision-making around CPM or tailored surveillance among patients with first primary BC. In particular, overestimation of risk can lead to recommending CPM among BC patients with low risks. Underestimation can lead to suboptimal surveillance or hesitance about recommending CPM for patients with substantial risk. Using individual patient data from multiple studies with long follow-up, we externally evaluated the prediction performance accuracy of CBCrisk, a tool developed and validated to provide individualized CBC risk prediction, and the Manchester formula, a heuristically derived calculation of $\mathrm{CBC}$ lifetime risk [6-9]. In addition, the availability of different European-descendent studies allowed heterogeneity in the performance by geographic area to be assessed.

CBCrisk under-predicted the risk of $\mathrm{CBC}$ and had moderate discrimination ability with considerable heterogeneity between studies. The Manchester formula was empirically derived from a systematic review, and its discrimination accuracy was higher than CBCrisk. This may be explained by the inclusion of $B R C A 1 / 2$ mutation carrier information, an important determinant of CBC risk [21]. With the same large individual patient data sets, PredictCBC models had been developed and validated [5]. In particular, PredictCBC version $1 \mathrm{~A}$ includes information of $B R C A 1 / 2$ mutation carriers and extensive information about the primary BC including treatments. The discrimination of all three prediction models was moderate, with AUC values around 0.6.

CBCrisk was previously externally validated using two independent clinical studies from Johns Hopkins University (JH) and MD Anderson Cancer Center (MDA) in the US [9]. Discrimination ability was 0.61 and 0.65 at 3 years, and 0.62 and 0.61 at 5 years for $\mathrm{JH}$ and MDA, respectively. The risk of $\mathrm{CBC}$ was overestimated in $\mathrm{JH}$ with $\mathrm{E} / \mathrm{O}$ ratios of 2.02 and 1.56 at 3 and 5 years, while underestimated in MDA with $\mathrm{E} / \mathrm{O}$ ratios of 0.61 and 0.62 , respectively.

The considerable heterogeneity in all CBC risk calculators, especially in the CBCrisk and the Manchester formula, reflects the different $\mathrm{CBC}$ incidences in every study [13]. Another potential source of heterogeneity is the carrier frequency of germline mutations associated with $\mathrm{CBC}$ that may vary among studies, especially in the CBC calculators not including information of BRCA1/2 mutation as CBCrisk and the PredictCBC-1B [22]. In addition, heterogeneity may be due to the different proportions of the use of (neo)adjuvant systemic therapies explained by the different distribution of tumor subtypes among studies [4]. Besides, inter-observer variation in pathological examination of BC among studies may lead to different adjuvant systemic therapy advice and, consequently, prediction of CBC risk [23]. Variation in prediction performance and limited generalizability of $\mathrm{CBC}$ risk calculators can also be partially explained by differences in how predictors are measured among studies [24, 25]. For example, lack of family history knowledge may lead to uncertainty in risk prediction and varies according to demographics of the patients [26]. In particular, if in some studies BC patients misreported information about family history, the CBC risk would be over(under)estimated causing inappropriate decision-making regarding CPM or tailored surveillance. Some limitations of our study must be recognized. First, our dataset, while large, had missing data for three covariates that were used in the CBCrisk model: breast density, age at first birth, and high-risk pre-neoplasia. The authors of CBCrisk estimated the relative risks for patients with the unknown characteristics, but the use of the missing indicator variable is suboptimal compared to having the prognostic information available. It may lead to over or under-estimation of absolute CBC risk [27]. For this reason, we suggest that it is preferable to use multiple imputation of missing data, as is done in the PredictCBC models $[28,29]$. In addition, investigation of the potential source of model misspecification due to possible different definitions or measurement error was not possible [30-32].

In conclusion, current statistical risk prediction models and heuristic formulas provided moderate CBC individualized prediction performance. Careful re-calibration is required before considering these models for clinical decision-making. A more direct comparison between the current $\mathrm{CBC}$ risk prediction models using a large external dataset with complete information on all factors included in all CBC prediction models would be ideal, but is currently unavailable. There is an ongoing debate about improvements of clinical prediction performance using machine learning approaches compared to standard regression approaches for risk prediction $[33,34]$. However, irrespective of the methodology, better predictors are needed to predict CBC more accurately. Deeper biological insights and potential inclusion of other genetic markers such as CHEK2 c.1100del mutation status and polygenic risk scores based on common genetic variants may improve $\mathrm{CBC}$ risk prediction, although rare mutations are unlikely to contribute substantially to $\mathrm{CBC}$ risk in the general population [35, 36]. Life-style factors such as body mass index, alcohol consumption, and smoking also may help to better stratify high- and low-CBC risk patients even though these factors are difficult to measure accurately. Moreover, breast density may be important. More detailed information about adjuvant systemic therapies may better identify patients with low- and high-CBC risk since chemotherapy and especially endocrine therapy reduce $\mathrm{CBC}$ risk [4]. After extension and further external validation of

\begin{tabular}{|l|l|l|l|l|}
\hline Journal : Large 10549 & Article No : 5611 & Pages : 12 & MS Code : 5611 & Dispatch : 30-3-2020 \\
\hline
\end{tabular}


prediction models for $\mathrm{CBC}$ risk, investigation of their potential clinical utility is an important future step.

Acknowledgements We thank all individuals who took part in these studies and all researchers, clinicians, technicians and administrative staff who have enabled this work to be carried out. ABCFS thank Maggie Angelakos, Judi Maskiell, Gillian Dite. ABCS and BOSOM thanks all the collaborating hospitals and pathology departments and many individual that made this study possible, specifically, we wish to acknowledge: Annegien Broeks, Sten Cornelissen, Frans Hogervorst, Laura van 't Veer, Floor van Leeuwen, Emiel Rutgers. EMC thanks J.C. Blom-Leenheer, P.J. Bos,C.M.G. Crepin and M. van Vliet for data management. CGPS thanks staff and participants of the Copenhagen General Population Study. For the excellent technical assistance: Dorthe Uldall Andersen, Maria Birna Arnadottir, Anne Bank, Dorthe Kjeldgård Hansen. HEBCS thanks Taru A. Muranen, Kristiina Aittomäki, Karl von Smitten, Irja Erkkilä. KARMA thanks the Swedish Medical Research Counsel. LMBC thanks Gilian Peuteman, Thomas Van Brussel, EvyVanderheyden and Kathleen Corthouts. MARIE thanks Petra Seibold, Dieter Flesch-Janys, Judith Heinz, Nadia Obi, Alina Vrieling, Sabine Behrens, Ursula Eilber, Muhabbet Celik, Til Olchers and Stefan Nickels. ORIGO thanks E. Krol-Warmerdam, and J. Blom for patient accrual, administering questionnaires, and managing clinical information. The authors thank the registration team of the Netherlands Comprehensive Cancer Organisation (IKNL) for the collection of data for the Netherlands Cancer Registry as well as IKNL staff for scientific advice. PBCS thanks Louise Brinton, Mark Sherman, Neonila Szeszenia-Dabrowska, Beata Peplonska, Witold Zatonski, Pei Chao, Michael Stagner. The ethical approval for the POSH study is MREC /00/6/69, UKCRN ID: 1137. We thank the SEARCH team.

Funding This work is supported by the Alpe d'HuZes/Dutch Cancer Society (KWF Kankerbestrijding) project 6253. BCAC is funded by Cancer Research UK [C1287/A16563, C1287/A10118], the European Union's Horizon 2020 Research and Innovation Programme (Grant Nos. 634935 and 633784 for BRIDGES and B-CAST respectively), and by the European Community's Seventh Framework Programme under grant agreement number 223175 (Grant No. HEALTHF2-2009-223175) (COGS). The EU Horizon 2020 Research and Innovation Programme funding source had no role in study design, data collection, data analysis, data interpretation or writing of the report. The Australian Breast Cancer Family Study (ABCFS) was supported by grant UM1 CA164920 from the National Cancer Institute (USA). The ABCFS was also supported by the National Health and Medical Research Council of Australia, the New South Wales Cancer Council, the Victorian Health Promotion Foundation (Australia) and the Victorian Breast Cancer Research Consortium. J.L.H. is a National Health and Medical Research Council (NHMRC) Senior Principal Research Fellow. M.C.S. is a NHMRC Senior Research Fellow. The ABCS study was supported by the Dutch Cancer Society [grants NKI 2007-3839; 2009 4363]. The work of the BBCC was partly funded by ELAN-Fond of the University Hospital of Erlangen. BOSOM was supported by the Dutch Cancer Society grant numbers DCS-NKI 2001-2423, DCSNKI 2007-3839, and DCSNKI 2009-4363; the Cancer Genomics Initiative; and notary office Spier \& Hazenberg for the coding procedure. The EMC was supported by grants from Alpe d'HuZes/Dutch Cancer Society NKI2013-6253 and from Pink Ribbon 2012.WO39.C143. The HEBCS was financially supported by the Helsinki University Hospital Research Fund, the Finnish Cancer Society, and the Sigrid Juselius Foundation. Financial support for KARBAC was provided through the regional agreement on medical training and clinical research (ALF) between Stockholm County Council and Karolinska Institutet, the Swedish Cancer Society, The Gustav V Jubilee foundation and Bert von Kantzows foundation. The KARMA study was supported by Märit and Hans Rausings Initiative Against Breast Cancer. LMBC is supported by the 'Stichting tegen Kanker'. The MARIE study was supported by the Deutsche Krebshilfe e.V.[70-2892-BR I, 106332, 108253, 108419, 110826, 110828], the Hamburg Cancer Society, the German Cancer Research Center (DKFZ) and the Federal Ministry of Education and Research (BMBF) Germany [01KH0402]. MEC was support by NIH grants CA63464, CA54281, CA098758, CA132839 and CA164973. The ORIGO study was supported by the Dutch Cancer Society (RUL 1997-1505) and the Biobanking and Biomolecular Resources Research Infrastructure (BBMRI-NL CP16). The PBCS was funded by Intramural Research Funds of the National Cancer Institute, Department of Health and Human Services, USA. Genotyping for PLCO was supported by the Intramural Research Program of the National Institutes of Health, NCI, Division of Cancer Epidemiology and Genetics. The POSH study is funded by Cancer Research UK (Grants C1275/A11699, C1275/C22524, C1275/A19187, C1275/A15956 and Breast Cancer Campaign 2010PR62, 2013PR044. PROCAS is funded from NIHR grant PGfAR 0707-10031. SEARCH is funded by Cancer Research UK [C490/A10124, C490/A16561] and supported by the UK National Institute for Health Research Biomedical Research Centre at the University of Cambridge. The University of Cambridge has received salary support for PDPP from the NHS in the East of England through the Clinical Academic Reserve. SKKDKFZS is supported by the DKFZ. The SZBCS (Szczecin Breast Cancer Study) was supported by Grant PBZ_KBN_122/P05/2004 and The National Centre for Research and Development (NCBR) within the framework of the international ERANET TRANSAN JTC 2012 application no. Cancer 12-054 (Contract No. ERA-NET-TRANSCAN / 07/2014).

\section{Compliance with ethical standards}

Conflict of interest Author DG, MH, EW, MAA, DA, JCB, CB, SEB, MKB, JCC, KC, PD, AMD, DFE, JF, HF, MGC, LH, CAH, PH, UH, JLH, AJ, AJ2, AJ3, RK, LBK, IK, DL, LLN, AL, JL, MM, LM, HN, HSAO, SP, PDPP, MS, SS, VTHBMS, MCS, WJT, RAEMT, AJvdB, CHMvD, FEvL, CvO, LvV, QW, CW, PJW, MJH declares that he has no conflict of interest. Author DMM declares that she receives a lecture fee from Pierre Fabre and personal fees for consultancy from Astra Zeneca. Author PAF reports grants from Novartis, grants from Biontech, personal fees from Novartis, personal fees from Roche, personal fees from Pfizer, personal fees from Celgene, personal fees from Daiichi-Sankyo, personal fees from TEVA, personal fees from Astra Zeneca, personal fees from Merck Sharp \& Dohme, personal fees from Myelo Therapeutics, personal fees from Macrogenics, personal fees from Eisai, personal fees from Puma, grants from Cepheid.

Ethical approval All procedures performed in studies involving human participants were in accordance with the ethical standards of international, national, and institutional research committees and with the 1964 Helsinki declaration and its later amendments or comparable ethical standards.

Informed consent Informed consent was obtained from all individual participants included in the study.

\section{References}

1. Langballe R, Frederiksen K, Jensen MB, Andersson M, CroninFenton D, Ejlertsen B, Mellemkjaer L (2018) Mortality after contralateral breast cancer in Denmark. Breast Cancer Res Treat 171(2):489-499. https://doi.org/10.1007/s10549-018-4846-3

2. Xiong Z, Yang L, Deng G, Huang X, Li X, Xie X, Wang J, Shuang Z, Wang X (2018) Patterns of occurrence and outcomes 
of contralateral breast cancer: analysis of SEER data. J Clin Med. https://doi.org/10.3390/jcm7060133

3. Wong SM, Freedman RA, Sagara Y, Aydogan F, Barry WT, Golshan M (2017) Growing use of contralateral prophylactic mastectomy despite no improvement in long-term survival for invasive breast cancer. Ann Surg 265(3):581-589. https://doi.org/10.1097/ SLA.0000000000001698

4. Kramer I, Schaapveld M, Oldenburg HSA, Sonke GS, McCool D, van Leeuwen FE, Van de Vijver KK, Russell NS, Linn SC, Siesling S, der Houven M-V, van Oordt CW, Schmidt MK (2019) The influence of adjuvant systemic regimens on contralateral breast cancer risk and receptor subtype. J Natl Cancer Inst. https://doi. org/10.1093/jnci/djz010

5. Giardiello D, Steyerberg EW, Hauptmann M, Adank MA, Akdeniz D, Blomqvist C, Bojesen SE, Bolla MK, Brinkhuis M, ChangClaude J, Czene K, Devilee P, Dunning AM, Easton DF, Eccles DM, Fasching PA, Figueroa J, Flyger H, Garcia-Closas M, Haeberle L, Haiman CA, Hall P, Hamann U, Hopper JL, Jager A, Jakubowska A, Jung A, Keeman R, Kramer I, Lambrechts D, Le Marchand L, Lindblom A, Lubinski J, Manoochehri M, Mariani L, Nevanlinna H, Oldenburg HSA, Pelders S, Pharoah PDP, Shah M, Siesling S, Smit V, Southey MC, Tapper WJ, Tollenaar R, van den Broek AJ, van Deurzen CHM, van Leeuwen FE, van Ongeval C, Van't Veer LJ, Wang Q, Wendt C, Westenend PJ, Hooning MJ, Schmidt MK (2019) Prediction and clinical utility of a contralateral breast cancer risk model. Breast Cancer Res 21(1):144. https ://doi.org/10.1186/s13058-019-1221-1

6. O’Donnell M (2018) Estimating Contralateral Breast Cancer Risk Curr Breast Cancer Rep 10(2):91-97

7. Chowdhury M, Euhus D, Onega T, Biswas S, Choudhary PK (2017) A model for individualized risk prediction of contralateral breast cancer. Breast Cancer Res Treat 161(1):153-160. https:// doi.org/10.1007/s10549-016-4039-x

8. Basu NN, Ross GL, Evans DG, Barr L (2015) The Manchester guidelines for contralateral risk-reducing mastectomy. World J Surg Oncol 13:237. https://doi.org/10.1186/s12957-015-0638-y

9. Chowdhury M, Euhus D, Arun B, Umbricht C, Biswas S, Choudhary $\mathrm{P}$ (2018) Validation of a personalized risk prediction model for contralateral breast cancer. Breast Cancer Res Treat. https:// doi.org/10.1007/s10549-018-4763-5

10. Chowdhury M, Euhus D, Onega T, Choudhary P (2017) CBCRisk: Contralateral Breast Cancer (CBC) Risk Predictor.

11. van den Broek AJ, Van't Veer LJ, Hooning MJ, Cornelissen S, Broeks A, Rutgers EJ, Smit VT, Cornelisse CJ, van Beek M, Janssen-Heijnen ML, Seynaeve C, Westenend PJ, Jobsen JJ, Siesling S, Tollenaar RA, van Leeuwen FE, Schmidt MK (2016) Impact of age at primary breast cancer on contralateral breast cancer risk in BRCA1/2 mutation carriers. J Clin Oncol 34(5):409-418. https ://doi.org/10.1200/JCO.2015.62.3942

12. Malone KE, Begg CB, Haile RW, Borg A, Concannon P, Tellhed L, Xue S, Teraoka S, Bernstein L, Capanu M, Reiner AS, Riedel ER, Thomas DC, Mellemkjaer L, Lynch CF, Boice JD Jr, Anton-Culver H, Bernstein JL (2010) Population-based study of the risk of second primary contralateral breast cancer associated with carrying a mutation in BRCA1 or BRCA2. J Clin Oncol 28(14):2404-2410. https://doi.org/10.1200/JCO.2009.24.2495

13. Austin PC, van Klaveren D, Vergouwe Y, Nieboer D, Lee DS, Steyerberg EW (2016) Geographic and temporal validity of prediction models: different approaches were useful to examine model performance. J Clin Epidemiol 79:76-85. https://doi. org/10.1016/j.jclinepi.2016.05.007

14. Michailidou K, Lindstrom S, Dennis J, Beesley J, Hui S, Kar S, Lemacon A, Soucy P, Glubb D, Rostamianfar A, Bolla MK, Wang Q, Tyrer J, Dicks E, Lee A, Wang Z, Allen J, Keeman R, Eilber U, French JD, Qing Chen X, Fachal L, McCue K, McCart Reed AE, Ghoussaini M, Carroll JS, Jiang X, Finucane H, Adams M, Adank
MA, Ahsan H, Aittomaki K, Anton-Culver H, Antonenkova NN, Arndt V, Aronson KJ, Arun B, Auer PL, Bacot F, Barrdahl M, Baynes C, Beckmann MW, Behrens S, Benitez J, Bermisheva M, Bernstein L, Blomqvist C, Bogdanova NV, Bojesen SE, Bonanni B, Borresen-Dale AL, Brand JS, Brauch H, Brennan P, Brenner H, Brinton L, Broberg P, Brock IW, Broeks A, Brooks-Wilson A, Brucker SY, Bruning T, Burwinkel B, Butterbach K, Cai Q, Cai H, Caldes T, Canzian F, Carracedo A, Carter BD, Castelao JE, Chan TL, David Cheng TY, Seng Chia K, Choi JY, Christiansen H, Clarke CL, Collaborators N, Collee M, Conroy DM, CordinaDuverger E, Cornelissen S, Cox DG, Cox A, Cross SS, Cunningham JM, Czene K, Daly MB, Devilee P, Doheny KF, Dork T, Dos-Santos-Silva I, Dumont M, Durcan L, Dwek M, Eccles DM, Ekici AB, Eliassen AH, Ellberg C, Elvira M, Engel C, Eriksson M, Fasching PA, Figueroa J, Flesch-Janys D, Fletcher O, Flyger H, Fritschi L, Gaborieau V, Gabrielson M, Gago-Dominguez M, Gao YT, Gapstur SM, Garcia-Saenz JA, Gaudet MM, Georgoulias V, Giles GG, Glendon G, Goldberg MS, Goldgar DE, GonzalezNeira A, Grenaker Alnaes GI, Grip M, Gronwald J, Grundy A, Guenel P, Haeberle L, Hahnen E, Haiman CA, Hakansson N, Hamann U, Hamel N, Hankinson S, Harrington P, Hart SN, Hartikainen JM, Hartman M, Hein A, Heyworth J, Hicks B, Hillemanns P, Ho DN, Hollestelle A, Hooning MJ, Hoover RN, Hopper JL, Hou MF, Hsiung CN, Huang G, Humphreys K, Ishiguro J, Ito H, Iwasaki M, Iwata H, Jakubowska A, Janni W, John EM, Johnson N, Jones K, Jones M, Jukkola-Vuorinen A, Kaaks R, Kabisch M, Kaczmarek K, Kang D, Kasuga Y, Kerin MJ, Khan S, Khusnutdinova E, Kiiski JI, Kim SW, Knight JA, Kosma VM, Kristensen VN, Kruger U, Kwong A, Lambrechts D, Le Marchand L, Lee E, Lee MH, Lee JW, Neng Lee C, Lejbkowicz F, Li J, Lilyquist J, Lindblom A, Lissowska J, Lo WY, Loibl S, Long J, Lophatananon A, Lubinski J, Luccarini C, Lux MP, Ma ESK, MacInnis RJ, Maishman T, Makalic E, Malone KE, Kostovska IM, Mannermaa A, Manoukian S, Manson JE, Margolin S, Mariapun S, Martinez ME, Matsuo K, Mavroudis D, McKay J, McLean C, MeijersHeijboer H, Meindl A, Menendez P, Menon U, Meyer J, Miao H, Miller N, Taib NAM, Muir K, Mulligan AM, Mulot C, Neuhausen SL, Nevanlinna H, Neven P, Nielsen SF, Noh DY, Nordestgaard BG, Norman A, Olopade OI, Olson JE, Olsson H, Olswold C, Orr N, Pankratz VS, Park SK, Park-Simon TW, Lloyd R, Perez JIA, Peterlongo P, Peto J, Phillips KA, Pinchev M, Plaseska-Karanfilska D, Prentice R, Presneau N, Prokofyeva D, Pugh E, Pylkas K, Rack B, Radice P, Rahman N, Rennert G, Rennert HS, Rhenius V, Romero A, Romm J, Ruddy KJ, Rudiger T, Rudolph A, Ruebner M, Rutgers EJT, Saloustros E, Sandler DP, Sangrajrang S, Sawyer EJ, Schmidt DF, Schmutzler RK, Schneeweiss A, Schoemaker MJ, Schumacher F, Schurmann P, Scott RJ, Scott C, Seal S, Seynaeve C, Shah M, Sharma P, Shen CY, Sheng G, Sherman ME, Shrubsole MJ, Shu XO, Smeets A, Sohn C, Southey MC, Spinelli JJ, Stegmaier C, Stewart-Brown S, Stone J, Stram DO, Surowy H, Swerdlow A, Tamimi R, Taylor JA, Tengstrom M, Teo SH, Beth Terry M, Tessier DC, Thanasitthichai S, Thone K, Tollenaar R, Tomlinson I, Tong L, Torres D, Truong T, Tseng CC, Tsugane S, Ulmer HU, Ursin G, Untch M, Vachon C, van Asperen CJ, Van Den Berg D, van den Ouweland AMW, van der Kolk L, van der Luijt RB, Vincent D, Vollenweider J, Waisfisz Q, Wang-Gohrke $\mathrm{S}$, Weinberg CR, Wendt C, Whittemore AS, Wildiers H, Willett W, Winqvist R, Wolk A, Wu AH, Xia L, Yamaji T, Yang XR, Har Yip C, Yoo KY, Yu JC, Zheng W, Zheng Y, Zhu B, Ziogas A, Ziv E, Investigators A, ConFab AI, Lakhani SR, Antoniou AC, Droit A, Andrulis IL, Amos CI, Couch FJ, Pharoah PDP, Chang-Claude J, Hall P, Hunter DJ, Milne RL, Garcia-Closas M, Schmidt MK, Chanock SJ, Dunning AM, Edwards SL, Bader GD, Chenevix-Trench G, Simard J, Kraft P, Easton DF (2017) Association analysis identifies 65 new breast cancer risk loci. Nature 551(7678):92-94. https://doi.org/10.1038/nature24284 
15. Blanche P, Dartigues JF, Jacqmin-Gadda H (2013) Estimating and comparing time-dependent areas under receiver operating characteristic curves for censored event times with competing risks. Stat Med 32(30):5381-5397. https://doi.org/10.1002/sim.5958

16. Blanche P, Kattan MW, Gerds TA (2018) The c-index is not proper for the evaluation of \$t\$-year predicted risks. Biostatistics. https://doi.org/10.1093/biostatistics/kxy006

17. Pfeiffer RM, Park Y, Kreimer AR, Lacey JV Jr, Pee D, Greenlee RT, Buys SS, Hollenbeck A, Rosner B, Gail MH, Hartge P (2013) Risk prediction for breast, endometrial, and ovarian cancer in white women aged $50 \mathrm{y}$ or older: derivation and validation from population-based cohort studies. PLoS Med 10(7):e1001492. https ://doi.org/10.1371/journal.pmed.1001492

18. Van Calster B, Nieboer D, Vergouwe Y, De Cock B, Pencina MJ, Steyerberg EW (2016) A calibration hierarchy for risk models was defined: from utopia to empirical data. J Clin Epidemiol 74:167-176. https://doi.org/10.1016/j.jclinepi.2015.12.005

19. Collins GS, Ogundimu EO, Altman DG (2016) Sample size considerations for the external validation of a multivariable prognostic model: a resampling study. Stat Med 35(2):214-226. https:// doi.org/10.1002/sim.6787

20. RDC Team (2017) A language and environment for statistical computing. R Foundation for Statistical Computing, Vienna

21. Akdeniz D, Schmidt MK, Seynaeve CM, McCool D, Giardiello D, van den Broek AJ, Hauptmann M, Steyerberg EW, Hooning MJ (2018) Risk factors for metachronous contralateral breast cancer: a systematic review and meta-analysis. Breast 44:1-14. https:// doi.org/10.1016/j.breast.2018.11.005

22. Armstrong N, Ryder S, Forbes C, Ross J, Quek RG (2019) A systematic review of the international prevalence of BRCA mutation in breast cancer. Clin Epidemiol 11:543-561. https://doi. org/10.2147/CLEP.S206949

23. Bueno-de-Mesquita JM, Nuyten DS, Wesseling J, van Tinteren $\mathrm{H}$, Linn SC, van de Vijver MJ (2010) The impact of inter-observer variation in pathological assessment of node-negative breast cancer on clinical risk assessment and patient selection for adjuvant systemic treatment. Ann Oncol 21(1):40-47. https://doi. org/10.1093/annonc/mdp273

24. Whittle R, Peat G, Belcher J, Collins GS, Riley RD (2018) Measurement error and timing of predictor values for multivariable risk prediction models are poorly reported. J Clin Epidemiol 102:38-49. https://doi.org/10.1016/j.jclinepi.2018.05.008

25. Luijken K, Groenwold RHH, Van Calster B, Steyerberg EW, van Smeden M (2019) Impact of predictor measurement heterogeneity across settings on the performance of prediction models: a measurement error perspective. Stat Med 38(18):3444-3459. https:// doi.org/10.1002/sim.8183

26. Pflieger LT, Mason CC, Facelli JC (2017) Uncertainty quantification in breast cancer risk prediction models using self-reported family health history. J Clin Transl Sci 1(1):53-59. https://doi. org/10.1017/cts.2016.9
27. Groenwold RH, White IR, Donders AR, Carpenter JR, Altman DG, Moons KG (2012) Missing covariate data in clinical research: when and when not to use the missing-indicator method for analysis. CMAJ 184(11):1265-1269. https://doi.org/10.1503/ cmaj.110977

28. Janssen KJ, Donders AR, Harrell FE Jr, Vergouwe Y, Chen Q, Grobbee DE, Moons KG (2010) Missing covariate data in medical research: to impute is better than to ignore. J Clin Epidemiol 63(7):721-727. https://doi.org/10.1016/j.jclinepi.2009.12.008

29. Janssen KJ, Vergouwe Y, Donders AR, Harrell FE Jr, Chen Q, Grobbee DE, Moons KG (2009) Dealing with missing predictor values when applying clinical prediction models. Clin Chem 55(5):994-1001. https://doi.org/10.1373/clinchem.2008.115345

30. Royston P, Altman DG (2013) External validation of a Cox prognostic model: principles and methods. BMC Med Res Methodol 13:33. https://doi.org/10.1186/1471-2288-13-33

31. van Houwelingen HC (2000) Validation, calibration, revision and combination of prognostic survival models. Stat Med 19(24):3401-3415

32. Pajouheshnia R, van Smeden M, Peelen LM, Groenwold RHH (2019) How variation in predictor measurement affects the discriminative ability and transportability of a prediction model. J Clin Epidemiol 105:136-141. https://doi.org/10.1016/j.jclin epi.2018.09.001

33. Christodoulou E, Ma J, Collins GS, Steyerberg EW, Verbakel JY, Van Calster B (2019) A systematic review shows no performance benefit of machine learning over logistic regression for clinical prediction models. J Clin Epidemiol 110:12-22. https://doi. org/10.1016/j.jclinepi.2019.02.004

34. Ming C, Viassolo V, Probst-Hensch N, Chappuis PO, Dinov ID, Katapodi MC (2019) Machine learning techniques for personalized breast cancer risk prediction: comparison with the BCRAT and BOADICEA models. Breast Cancer Res 21(1):75. https://doi. org/10.1186/s13058-019-1158-4

35. Torkamani A, Wineinger NE, Topol EJ (2018) The personal and clinical utility of polygenic risk scores. Nat Rev Genet 19(9):581590. https://doi.org/10.1038/s41576-018-0018-x

36. Mellemkjaer L, Dahl C, Olsen JH, Bertelsen L, Guldberg P, Christensen J, Borresen-Dale AL, Stovall M, Langholz B, Bernstein L, Lynch CF, Malone KE, Haile RW, Andersson M, Thomas DC, Concannon P, Capanu M, Boice JD Jr, Group WSC, Bernstein JL (2008) Risk for contralateral breast cancer among carriers of the CHEK2*1100delC mutation in the WECARE Study. Br J Cancer 98(4):728-733. https://doi.org/10.1038/sj.bjc.6604228

Publisher's Note Springer Nature remains neutral with regard to jurisdictional claims in published maps and institutional affiliations.
613

614

615

616

617

618

619

620

621

622

623

624

625

626

627

628

629

630

631

632

633

634

635

636

637

638

639

640

641

642

643

644

645

646

647

648

649

650

651

652

653

654

655

656

657

658

659

\section{Affiliations}

Daniele Giardiello ${ }^{1,2} \cdot$ Michael Hauptmann $^{3,4}$. Ewout W. Steyerberg ${ }^{2,5}$. Muriel A. Adank ${ }^{6}$. Delal Akdeniz ${ }^{7}$. Jannet C. Blom ${ }^{7}$. Carl Blomqvist ${ }^{8,9}$. Stig E. Bojesen ${ }^{10,11,12}$. Manjeet K. Bolla ${ }^{13}$. Mariël Brinkhuis ${ }^{14}$. Jenny Chang-Claude ${ }^{15,16} \cdot$ Kamila Czene $^{17}$. Peter Devilee ${ }^{18,19}$. Alison M. Dunning ${ }^{20}$. Douglas F. Easton ${ }^{13,20}$. Diana M. Eccles ${ }^{21}$. Peter A. Fasching ${ }^{22,23}$. Jonine Figueroa ${ }^{24,25,26}$ • Henrik Flyger ${ }^{27}$ - Montserrat García-Closas ${ }^{26,28}$. Lothar Haeberle ${ }^{23}$. Christopher A. Haiman ${ }^{29}$. Per Hall ${ }^{17,30}$. Ute Hamann ${ }^{31}$. John L. Hopper ${ }^{32}$. Agnes Jager ${ }^{33} \cdot$ Anna Jakubowska ${ }^{34,35} \cdot$ Audrey Jung ${ }^{15} \cdot$ Renske Keeman $^{1} \cdot$ Linetta B. Koppert $^{36} \cdot$ Iris Kramer $^{1}$. Diether Lambrechts ${ }^{37,38}$. Loic Le Marchand ${ }^{39}$. Annika Lindblom ${ }^{40,41}$. Jan Lubiński ${ }^{34}$. Mehdi Manoochehri ${ }^{31}$. Luigi Mariani $^{42} \cdot$ Heli Nevanlinna ${ }^{43} \cdot$ Hester S. A. Oldenburg ${ }^{44} \cdot$ Saskia Pelders $^{7}$. Paul D. P. Pharoah ${ }^{13,20} \cdot$ Mitul Shah $^{20}$. 
Sabine Siesling ${ }^{45}$-Vincent T. H. B. M. Smit ${ }^{18} \cdot$ Melissa C. Southey $^{46,47} \cdot$ William J. Tapper $^{48} \cdot$ Rob A. E. M. Tollenaar ${ }^{49}$. Alexandra J. van den Broek ${ }^{1}$. Carolien H. M. van Deurzen ${ }^{50}$ • Flora E. van Leeuwen ${ }^{51}$. Chantal van Ongeval ${ }^{52}$. Laura J. Van't Veer ${ }^{1}$. Qin Wang ${ }^{13}$. Camilla Wendt ${ }^{53}$. Pieter J. Westenend ${ }^{54} \cdot$ Maartje J. Hooning ${ }^{7}$. Marjanka K. Schmi $\mathrm{dt}^{1,51,55}$

1 Division of Molecular Pathology, The Netherlands Cancer Institute - Antoni Van Leeuwenhoek Hospital, Amsterdam, The Netherlands

2 Department of Biomedical Data Sciences, Leiden University Medical Center, Leiden, The Netherlands

3 Brandenburg Medical School, Institute of Biostatistics and Registry Research, Neuruppin, Germany

4 Department of Epidemiology and Biostatistics, The Netherlands Cancer Institute - Antoni Van Leeuwenhoek Hospital, Amsterdam, The Netherlands

5 Department of Public Health, Erasmus MC Cancer Institute, Rotterdam, The Netherlands

6 Family Cancer Clinic, The Netherlands Cancer Institute - Antoni Van Leeuwenhoek Hospital, Amsterdam, The Netherlands

7 Department of Medical Oncology, Family Cancer Clinic, Erasmus MC Cancer Institute, Rotterdam, The Netherlands

8 Department of Oncology, Helsinki University Hospital, University of Helsinki, Helsinki, Finland

9 Department of Oncology, Örebro University Hospital, Örebro, Sweden

10 Copenhagen General Population Study, Herlev and Gentofte Hospital, Copenhagen University Hospital, Herlev, Denmark

11 Department of Clinical Biochemistry, Herlev and Gentofte Hospital, Copenhagen University Hospital, Herlev, Denmark

12 Faculty of Health and Medical Sciences, University of Copenhagen, Copenhagen, Denmark

13 Centre for Cancer Genetic Epidemiology, Department of Public Health and Primary Care, University of Cambridge, Cambridge, UK

14 Laboratory for Pathology, East-Netherlands, Hengelo, The Netherlands

15 Division of Cancer Epidemiology, German Cancer Research Center (DKFZ), Heidelberg, Germany

16 University Medical Center Hamburg-Eppendorf, Cancer Epidemiology Group, University Cancer Center Hamburg (UCCH), Hamburg, Germany

17 Department of Medical Epidemiology and Biostatistics, Karolinska Institutet, Stockholm, Sweden

18 Department of Pathology, Leiden University Medical Center, Leiden, The Netherlands

19 Department of Human Genetics, Leiden University Medical Center, Leiden, The Netherlands

20 Centre for Cancer Genetic Epidemiology, Department of Oncology, University of Cambridge, Cambridge, UK
21 Cancer Sciences Academic Unit, Faculty of Medicine, University of Southampton, Southampton, UK

22 David Geffen School of Medicine, Department of Medicine Division of Hematology and Oncology, University of California At Los Angeles, Los Angeles, CA, USA

23 University Hospital Erlangen, Department of Gynecology and Obstetrics, Comprehensive Cancer Center ER-EMN, Friedrich-Alexander-University Erlangen-Nuremberg, Erlangen, Germany

24 The University of Edinburgh Medical School, Usher Institute of Population Health Sciences and Informatics, Edinburgh, UK

25 Cancer Research UK Edinburgh Centre, Edinburgh, UK

26 Department of Health and Human Services, Division of Cancer Epidemiology and Genetics, National Cancer Institute, National Institutes of Health, Bethesda, MD, USA

27 Department of Breast Surgery, Herlev and Gentofte Hospital, Copenhagen University Hospital, Herlev, Denmark

28 Division of Genetics and Epidemiology, Institute of Cancer Research, London, UK

29 Department of Preventive Medicine, Keck School of Medicine, University of Southern California, Los Angeles, CA, USA

30 Department of Oncology, Södersjukhuset, Stockholm, Sweden

31 Molecular Genetics of Breast Cancer, German Cancer Research Center (DKFZ), Heidelberg, Germany

32 Centre for Epidemiology and Biostatistics, Melbourne School of Population and Global Health, The University of Melbourne, Melbourne, VIC, Australia

33 Department of Medical Oncology, Erasmus MC Cancer Institute, Rotterdam, The Netherlands

34 Department of Genetics and Pathology, Pomeranian Medical University, Szczecin, Poland

35 Independent Laboratory of Molecular Biology and Genetic Diagnostics, Pomeranian Medical University, Szczecin, Poland

36 Department of Surgical Oncology, Erasmus MC Cancer Institute, Rotterdam, The Netherlands

37 VIB Center for Cancer Biology, Leuven, Belgium

38 Laboratory for Translational Genetics, Department of Human Genetics, University of Leuven, Leuven, Belgium

39 Epidemiology Program, University of Hawaii Cancer Center, Honolulu, HI, USA

40 Department of Molecular Medicine and Surgery, Karolinska Institutet, Stockholm, Sweden 
41 Department of Clinical Genetics, Karolinska University Hospital, Stockholm, Sweden

42 Unit of Clinical Epidemiology and Trial Organization, Fondazione IRCCS Istituto Nazionale Dei Tumori, Milan, Italy

43 Department of Obstetrics and Gynecology, Helsinki University Hospital, University of Helsinki, Helsinki, Finland

44 Department of Surgical Oncology, The Netherlands Cancer Institute - Antoni Van Leeuwenhoek Hospital, Amsterdam, The Netherlands

45 Department of Research, Netherlands Comprehensive Cancer Organisation, Utrecht, The Netherlands

46 Precision Medicine, School of Clinical Sciences at Monash Health, Monash University, Clayton, VIC, Australia

47 Department of Clinical Pathology, The University of Melbourne, Melbourne, VIC, Australia

48 Faculty of Medicine, University of Southampton, Southampton, UK
Department of Surgery, Leiden University Medical Center, Leiden, The Netherlands

50 Department of Pathology, Erasmus MC Cancer Institute, Rotterdam, The Netherlands

51 Division of Psychosocial Research and Epidemiology, The Netherlands Cancer Institute - Antoni Van Leeuwenhoek Hospital, Amsterdam, The Netherlands

52 Leuven Cancer Institute, Leuven Multidisciplinary Breast Center, Department of Oncology, University Hospitals Leuven, Leuven, Belgium

53 Department of Clinical Science and Education, Karolinska Institutet, Södersjukhuset, Stockholm, Sweden

54 Laboratory for Pathology, Dordrecht, The Netherlands

55 Netherlands Cancer Institute, Plesmanlaan 121, 1066 CX Amsterdam, The Netherlands 